\title{
AS BOAS PRÁTICAS DE GOVERNANÇA: UM ESTUDO SOBRE A TRANSPARÊNCIA E PRESTAÇÃO DE CONTAS NAS OSCIPs DO RS
}

\section{Raiziane Cássia Freire da Silva}

Graduada em Ciências Contábeis pela Universidade Regional Integrada do Alto Uruguai e das Missões raifreire@hotmail.com

\section{Rosane Maria Seibert}

Doutoranda em Ciências Contábeis pela Universidade do Vale do Rio dos Sinos, UNISINOS Professora da Universidade Regional Integrada do Alto Uruguai e das Missões - URI rseibert@santoangelo.uri.br

\section{Berenice Beatriz Rossner Wbatuba}

Doutoranda em Desenvolvimento Regional pela Universidade de Santa Cruz do Sul - UNISC Professora da Universidade Regional Integrada do Alto Uruguai e das Missões - URI bwbatuba@santoangelo.uri.br

Clea Beatriz Macagnan

Doutor em Creación, estrategia y gestión de empresas pela Universitat Autònoma de Barcelona - UAB cleabeatrizm@gmail.com

\section{RESUMO}

Objetivo desse estudo foi identificar quais são as informações disponibilizadas pelas Organizações da Sociedade Civil de Interesse Público (Oscips) do Estado do Rio Grande do Sul, como prestação de contas, aos seus públicos de interesse, em seus sítios de internet. A amostra foi de 89 organizações. A abordagem metodológica utilizada foi qualitativa e a coleta de evidências, bibliográfica, documental e observação não-participante nos sites das Oscips. As evidências foram tratadas por meio de estatística descritiva e análise de conteúdo. Os resultados sugerem que as informações evidenciadas são insuficientes para se caracterizar como adequadas à prestação de contas aos seus stakeholders, o que demonstra a falta de transparência e a necessidade de melhoria do seu sistema de governança, principalmente no atendimento aos princípios de transparência e de prestação de contas. Essa pesquisa limitou-se às informações disponíveis nos sítios de internet, sem acesso às evidências restritas às dependências das organizações e aos seus membros, o que remete a necessidade de outras pesquisas sobre esse tema.

Palavras-chave: Governança; Oscips; Prestação de contas; Transparência.

\section{THE GOOD PRACTICES OF GOVERNANCE: A STUDY ON THE TRANSPARENCY AND ACCOUNTABILITY IN THE OSCIPs - RS}

\begin{abstract}
The aim of the study was to identify what are the information provided by Civil Society Organizations of Public Interest (Oscips) of Rio Grande do Sul State as accountability to their stakeholders on their internet sites. The sample consisted of 89 organizations. The methodological approach was qualitative and the data collection was bibliographical, documentary and nonparticipant observation on the websites of OSCIPs. The evidence was treated through descriptive statistics and content analysis. The results suggest that the information highlighted are insufficient to characterize as proper accountability to the stakeholders, which shows the lack of transparency and the need to improve their governance system, especially in meeting the principles of transparency and provision of financial accounts. The research focused on limited information available on the internet sites without access to restricted data and dependencies of organizations and their members so we suggest the need for further research on the topic.
\end{abstract}

Keywords: Accountability; Governance; Oscips; Transparency. 


\section{INTRODUÇÃO}

As constantes modificações no cenário econômico passaram a exigir das organizações o desenvolvimento de estratégias para sobrevivência neste meio oscilante e competitivo. Assim, o tema governança vem difundindo-se como forma estratégica para garantir a competitividade e a perenidade das organizações (Weitzner \& Peridis, 2011; McDonnell, 2011) pela adoção das boas práticas de governança, que são fundamentadas em princípios, tais como a transparência, a responsabilidade organizacional e a prestação de contas.

Esses princípios, por sua vez, são norteados pelas teorias da legitimidade e dos stakeholders, que preconizam que a transparência, a prestação de contas e a responsabilidade social têm se configurado como necessárias para a legitimação das organizações na sociedade onde estão inseridas (Gray, 2002; O’Dwyer, 2003). As organizações precisam demonstrar o cumprimento do contrato social (implícito ou explicito) com retorno social adequado, para que seus stakeholders lhes concedam o direito de permanecer atuando naquela comunidade (Shocker \& Sethi, 1973; Lindblom, 1994; Suchman, 1995; Freeman, 2000; Freeman \& McVea, 2001; Parmar et al., 2010).

As boas práticas de governança não se restringem, apenas, às sociedades anônimas de capital aberto ou fechado, podendo ser adotadas por qualquer tipo de organização, independentemente de sua natureza ou porte, como, por exemplo, as Organizações da Sociedade Civil de Interesse Público - Oscips, Instituto Brasileiro de Governança Corporativa [IBGC] \& Grupo de Institutos Fundações e Empresas [GIFE], 2014). No entanto, o terceiro setor da economia, onde estão inseridas as Oscips, ainda tem sido pouco explorado, configurando-se como uma lacuna nas pesquisas sobre o tema (Lambell, et al., 2008).

Oscip é uma qualificação concedida pelo Ministério da Justiça, desde 1999, com a promulgação da Lei $n^{\circ} 9.790$ (1999). A partir de então, mais de quatro mil Organizações de direito privado, sem fins lucrativos, se qualificaram como Oscips no Brasil (Ministério da Justiça, 2015). Todas essas Organizações possuem vantagens derivadas desta qualificação devendo, em contrapartida, cumprir algumas exigências legais essencialmente baseadas nos princípios da transparência, responsabilidade social e prestação de contas.

A inobservância da lei acarreta a perda da qualificação (Lei 9.790, 1999), por isso, se presumiu que a maioria das Oscips brasileiras divulgou suas informações socioeconômicos e realizou as prestações de contas em conformidade com a legislação. No entanto, a redação da lei que regula as Oscips não é taxativa ao relacionar a composição da prestação de contas ao público, estabelecendo apenas o mínimo a ser apresentado.

Dessa forma, ao se deparar com a flexibilidade da legislação e reconhecendo a importância da adoção das boas práticas de governança, principalmente dos princípios da transparência, da responsabilidade organizacional e da prestação de contas das organizações para com seus públicos de interesse, sua legitimidade se fortalece (Phillips, 2003; Parmar et al., 2010; Ibgc \& Gife, 2014). Nesse contexto, essa pesquisa buscou responder a seguinte questão: "Quais são as informações disponibilizadas pelas Oscips, como prestação de contas aos seus públicos de interesse, por meio de suas páginas eletrônicas de Internet?" Desse modo, o objetivo principal desse estudo foi identificar quais são as informações disponibilizadas pelas Oscips do Estado do Rio Grande do Sul, como prestação de contas aos seus públicos de interesse, em suas páginas eletrônicas de Internet.

Além desta introdução, esse artigo apresenta a revisão da literatura que fundamentou este estudo, descreve o processo metodológico adotado para o desenvolvimento da pesquisa, os resultados encontrados e a discussão desses resultados. Finalizando, tem-se as considerações finais.

\section{REVISÃO DA LITERATURA}

Neste tópico, são abordados alguns temas, tais como a governança das organizações, algumas das suas teorias de base e seus princípios, bem como conceituam-se Oscips. Assuntos que serviram de fundamentação para a pesquisa. 


\subsection{Governança das organizações}

O tema governança é considerado relativamente recente, dado o surgimento desta expressão no início dos anos 1980, porém, as discussões sobre o motivo (a separação entre a propriedade e o controle das organizações) que levaram ao despertar da governança é mais antigo que a própria expressão Governança Corporativa.

Berle \& Means (1932), pioneiros, ao abordar as divergências dos interesses decorridos da separação entre propriedade e controle. O crescimento em número e poder das sociedades anônimas são fatores responsáveis pela separação da pessoa do proprietário e a pessoa do administrador da empresa, eclodindo na necessidade de escolha do empregado que garanta o funcionamento da organização em consonância com os interesses dos proprietários.

Outros pesquisadores vêm aprofundando as discussões relativas às grandes corporações e perpassam por Coase (1937) argumentando sobre a natureza da firma, depois Alchian \& Demsetz (1972), tratando da separação entre propriedade e controle, e Jensen \& Meckling (1976), abordando os conflitos de interesse entre o agente e o principal. Então, na existência dos conflitos de interesses e nos custos gerados para controlar essas divergências, surge a governança visando proteger a organização (Jensen \& Meckling, 1976). Neste contexto, esse tema tem sido amplamente explorado em estudos que tem como objeto de pesquisa as grandes corporações.

Por outro lado, existe a vertente das teorias sociais que incluem a teoria da legitimidade e a dos stakeholders. A Teoria da Legitimidade parte do pressuposto de que a relação entre a organização e a sociedade em que está inserida é regida por um "contrato social" que identifica as expectativas explícitas (determinadas por lei) e as implícitas (aquelas que a lei não abrange) das partes que integram a organização e determinam como ela deve se comportar (Deegan et al.,2002). Ao seguir o comportamento orientado por este contrato social, a organização seria legitimada por seus stakeholders. Legitimidade é "[...]uma percepção ou suposição generalizada de que as ações de uma entidade são desejáveis, apropriadas ou adequadas ao sistema socialmente construído de normas, valores, crenças e definições" (Suchman, 1995, p. 574). Logo, sob a ótica dessa teoria, uma organização será legítima quando cumprir com as expectativas explícitas e implícitas do seu contrato com a sociedade, devolvendo algo do interesse dessa sociedade para merecer permanecer nela (Shocker \& Sethi, 1973; Lindblom, 1994; Suchman, 1995).

A teoria dos stakeholders parte do princípio de que as organizações não devem atender apenas aos interesses dos proprietários, mas também das demais partes envolvidas. Podem ser muitos os interessados nas organizações, entre eles destacam-se: investidores, governo, empregados, fornecedores, credores, público em geral (Dantas et al., 2004; Parmar et al, 2010) ou, simplesmente, os stakeholders (Freeman, 2000; Freeman \& McVea, 2001). O termo stakeholders pode ser definido como qualquer grupo ou indivíduo afetado ou que possa afetar a organização na realização de seus objetivos (Freeman, 2000; Freeman \& McVea, 2001; Parmar et al., 2010; Machado, 2011).

Cabe a organização envolver seus stakeholders nas suas políticas e, principalmente, prestar contas a eles, pois eles têm poder para formar grupos de pressão contra as organizações e gerar custos sociais, tais como a perda da reputação (Michelon, 2011) e da legitimidade (Lindblom, 1994; Suchman, 1995), e custos políticos, tais como a perda de benefícios fiscais concedidos pelos governos (Watts \& Zimmerman, 1978; Wagenhofer, 1990). O setor político é considerado um dos stakeholders (Parmar et al 2010) e possui poder para transferir riquezas a vários grupos sociais (Watts \& Zimmerman, 1978; Wagenhofer, 1990). A organização é sensível a regulação, nacionalização, expropriação, dentre outras ações governamentais passíveis de imposição (Shaffer, 1995; Álvarez, Sánchez \& Domínguez, 2008). As organizações utilizam-se de artifícios, dentre eles a seleção de procedimentos contábeis e a gestão dos accruals (Dechow, Ge, \& Schrand, 2010), para diminuir seus ganhos e a evidenciação (Verrecchia, 1983; 2001) e desviar a atenção da geração de altos lucros, objetivando reduzir a probabilidade de ações políticas adversas que possam afetar negativamente os resultados da organização (Watts \& Zimmerman, 1978; Wagenhofer, 1990). Assim, organizações com possíveis custos políticos, ao sentirem sua legitimidade ameaçada, 
usariam a evidenciação compulsória e voluntária como uma forma de contornar a situação e, ainda, evitar ou minimizar a intervenção política em suas atividades, por meio de restrições legais, impostos e outros (Álvarez, Sánchez \& Domínguez, 2008; Beuren \& Sothe, 2009, Rover et al., 2012). Neste contexto, a abordagem da governança é ampliada para incluir todas as demais partes relacionadas às organizações (Phillips, 2003; Parmar et al., 2010).

A governança pode ser definida como o sistema que dirige, monitora e incentiva as organizações, envolvendo os relacionamentos entre proprietários, Conselho de Administração, diretoria e órgãos de controle. Por meio das boas práticas de governança, seus princípios são transformados em recomendações a fim de alinhar os interesses de todas as partes interessadas, e, assim, preservar e otimizar o valor da organização, facilitando o acesso ao capital, além de contribuir para a sua perenidade (IBGC, 2009).

As boas práticas de governança não se limitam apenas às organizações que visam lucros, podendo igualmente ser adotadas pelas organizações com fins não econômicos. No caso dessas organizações, a governança se faz necessária para reformular a maneira como elas vêm sendo administradas, acrescentando novos instrumentos para a melhoria de sua gestão, principalmente por enfrentarem desafios que podem ameaçar sua sobrevivência, como, por exemplo, a legitimidade (Salamon, 1997; Hudson, 1999; Coelho, 2000; Leal \& Famá, 2007).

As boas práticas de governança são fundamentadas em princípios basilares (Slomski et al., 2008) e visam ao alinhamento dos interesses, à melhoria do desempenho da gestão e agregação de valor perante o mercado (Ibgc, 2009). Conforme a Ocde (2004), os princípios da governança são: Garantir a base de uma estrutura efetiva de governança; direito dos acionistas; tratamento equitativo dos acionistas; papel dos stakeholders; divulgação e transparência; responsabilidade do Conselho. A partir desses princípios, o Ibgc (2009) adapta-os para quatro princípios básicos, que são difundidos no Brasil:

\begin{tabular}{|l|l|}
\hline \multicolumn{1}{|c|}{ PRINCÍPIOS } & \multicolumn{1}{c|}{ DESCRIÇÃO } \\
\hline Equidade (fainerss) & $\begin{array}{l}\text { Referente ao tratamento igualitário e justo de todos os sócios e demais } \\
\text { stakeholders, não sendo aceitas atitudes ou políticas discriminatórias. }\end{array}$ \\
\hline $\begin{array}{l}\text { Prestação de contas } \\
\text { (accountability) }\end{array}$ & $\begin{array}{l}\text { Sócios, gestores, conselheiros e auditores devem prestar contas de sua atuação e } \\
\text { se responsabilizarem integralmente pelas consequências de seus atos e omissões. }\end{array}$ \\
\hline $\begin{array}{l}\text { Responsabilidade social } \\
\text { organizacional }\end{array}$ & $\begin{array}{l}\text { Dever de zelar pela sustentabilidade da organização visando sua perenidade, } \\
\text { considerando em seus negócios e operações as questões sociais e ambientais. }\end{array}$ \\
\hline Transparência (disclosure) & $\begin{array}{l}\text { Relacionado à disponibilização de informações compulsórias e voluntárias para as } \\
\text { partes interessadas, principalmente aqueles relevantes para ações gerenciais e que } \\
\text { conduzem a criação de valor. A adequada transparência resulta em confiança } \\
\text { interna e nas relaçôes externas. }\end{array}$ \\
\hline
\end{tabular}

Figura 1. Princípios Governança Ibgc

Fonte: Ibgc, 2009 destacados.

Para esta pesquisa, três dos princípios preconizados pelo Ibgc (2009) merecem ser

\subsection{Prestação de contas e transparência}

Prestação de contas e transparência são dois princípios que não se separam, pois a prestação de contas é um instrumento de transparência no processo de gestão de uma organização (Gimenes, 2010), podendo ocorrer de forma compulsória ou voluntária (Dantas et al., 2004; Beuren \& Sothe, 2009). Por compulsória, entende-se aquelas informações prestadas em decorrência de exigências legais dos órgãos reguladores e das entidades de classe, enquanto a voluntária são todas as informações prestadas pela organização que não possuem obrigatoriedade legal de evidenciação (Beuren, Hein \& Boff, 2011). Por meio desta, a organização estará se associando o seu ato ao cumprimento ético e moral, demonstrando ser socialmente responsável, além de fortalecer sua legitimação, o que contribuirá para o aumento da credibilidade dos seus stakeholders, minimizar o 
risco de ataques de grupos de pressão social, e, assim, demonstrar princípios de gestão que, por sua vez, irão agregar valor (O’Donovan, 2002; Dantas et al., 2004; Álvarez, Sánchez \& Domínguez, 2008; Beuren, Hein \& Boff, 2011; Rover et al., 2012; Williams \& Adams, 2013).

A prestação de contas é a capacidade de resposta ou a responsividade das organizações para questões das partes interessadas que afetam o seu desempenho de sustentabilidade e é realizada por meio de decisões, ações e desempenho, bem como a comunicação com as partes interessadas (Accountability, 2008). Já a transparência é mais ampla que a simples obrigação de divulgar (Ibgc, 2009), nesse aspecto, ser transparente seria evidenciar tempestivamente informações qualitativas e quantitativas detalhadas, financeiras ou não, relevantes e compreensíveis para que seus usuários possam entender os riscos e as atividades organizacionais, a fim de evitar possíveis erros ou perdas, mesmo que a organização ponha em risco sua posição perante a concorrência (Ocde, 2004; Dantas et al., 2004). Por outro lado, Verrecchia (1983; 2001) argumenta a necessidade de evidenciação discricionária, ou seja, a organização deve ser transparente buscando um equilíbrio entre os custos e os benefícios de evidenciar. O principal custo da evidenciação seria a perda de vantagem competitiva (Dye, 1986). Assim, existiria a necessidade de gestão no estabelecimento das políticas de transparência e prestação de contas das organizações (Dye, 1986; Verrecchia, 1983; 2001).

Para O'Donovan (2002), as organizações devem ser transparentes e prestar contas aos seus públicos de interesse, projetando uma imagem favorável da organização ou fazer esforços de legitimação para evitar os malefícios da perda da legitimidade, os conflitos e a diminuição do apoio social, pois o objetivo da organização é ser legítima. Além disso, as expectativas sociais mudam ao longo do tempo e as organizações precisam monitorar as mudanças nos interesses de seus públicos para que continuem sendo percebidas como legítimas (Patten; 1991; Lindblom; 1994; Deegan et al., 2002; O’Donovan; 2002). Nesse sentido, os princípios da boa governança contribuem para demonstrar que as organizações acompanham as mudanças nas expectativas sociais.

Em síntese, os resultados gerados pelas atividades da organização devem maximizar não apenas os interesses dos proprietários, mas também de todas as outras partes envolvidas (Freeman, 2000; Verrecchia 2001; Parmar et al., 2010). Ainda, o bom desempenho da organização está ligado com a boa relação com seus stakeholders que devem ser reconhecidos e considerados tanto na estrutura e política organizacional da organização quanto na tomada de decisões, pois o equilíbrio dessa relação é fundamental para a legitimação e a sobrevivência da organização (Phillips, 2003; Freeman, 2000; Parmar et al., 2010). Assim, a prestação de contas e a transparência adequadas são meios para o relacionamento da organização com seus stakeholders.

Diversos estudos têm explorado o tema evidenciação da responsabilidade social das organizações, como forma de prestação de contas e de transparência, bem como de melhoria das práticas de governança das organizações. Entre eles, destacam-se:

\begin{tabular}{|l|l|}
\hline \multicolumn{1}{|c|}{ ASSUNTO ABORDADO } & \multicolumn{1}{|c|}{ AUTORES E ANO DE PUBLICAÇÃO } \\
\hline $\begin{array}{l}\text { A evidenciação da } \\
\text { responsabilidade social e os } \\
\text { princípios e as práticas da } \\
\text { governança. }\end{array}$ & Avelino, Pinheiro \& Lamounier, 2012; Burritt, 2012; Michelon \& Parbonetti, \\
\hline $\begin{array}{l}\text { A evidenciação da } \\
\text { responsabilidade social e os } \\
\text { stakeholders. }\end{array}$ & $\begin{array}{l}\text { Bezerra et al.; 2014; Duff, 2014; Drobetz, et al., 2014; Cunha, et al., 2015; Lys, } \\
\text { Naughton \& Wang, 2015; Marquezan, et al., 2015.. }\end{array}$ \\
\hline $\begin{array}{l}\text { Teoria da legitimidade e a } \\
\text { evidenciação das organizações. }\end{array}$ & $\begin{array}{l}\text { Adams, 2013; Araújo Junior, et al., 2014; Mzembe \& Downs, 2014; Park, } \\
\text { Chidlou \& Choi, 2014; Saat \& Selamat, 2014; Jo, Song \& Tsang, 2015; Pérez } \\
\text { \& Bosque, 2015. }\end{array}$ \\
\hline
\end{tabular}

Figura 2: Estudos empíricos sobre evidenciação da responsabilidade social das organizações

Fonte: Elaborado pelas autoras

A evidenciação da responsabilidade social das organizações teria como objetivo, além de valor econômico, a busca por valor social junto aos seus stakeholders (Core, Guay, \& Verdi, 2006). 


\subsection{Responsabilidade social}

O conceito de reponsabilidade social tem evoluído alicerçado no princípio de que as organizações precisam tomar decisões e agir de forma socialmente sustentável. No entanto, a falta de consenso e de clareza sobre o significado de responsabilidade social tem levado a discussões frequentes (Carroll 1979; 1999; Wood, 1991; Ashley, Coutinho \& Tomei 2000; O'Dwyer, 2003).

Os conceitos encontrados na literatura transitam desde uma visão puramente econômica, que entende que a responsabilidade das organizações está em gerar retorno econômico para os detentores do capital, até uma visão mais abrangente, associando a responsabilidade social à filantropia. Carroll (1979) reconhece que o conceito muda para atender as necessidades da sociedade. Por outro lado, há concordância de que responsabilidade social é um comportamento que os públicos pertinentes alegam ser esperado pela sociedade ou moralmente necessário e, portanto, justificadamente exigido das organizações (Carroll 1979; 1999; Whetten, Rands \& Godfrey, 2002). Portanto, apesar da crença de alguns de que responsabilidade social é apenas a prática de ações sociais (Melo \& Froes, 2001; Machado, 2011), a sua lógica está atrelada à ideia dos stakeholders. A responsabilidade social parte da premissa de que a sociedade tem expectativas sobre o comportamento e o resultado das atividades realizadas pela organização devido à ligação existente entre elas (Machado, 2011; Rahin, 2012). Assim, uma organização socialmente responsável toma decisões observando o respeito pelas pessoas, pela comunidade e pelo meio ambiente, se comunica tentando ser transparente e dar retorno aos investidores, se preocupa com o ambiente de trabalho, o bem-estar de seus funcionários e dependentes, a satisfação de seus clientes e a sinergia com seus parceiros (Melo \& Froes, 2001).

Para atender a gama de obrigações das organizações para com a sociedade, Carroll (1979) propõe que o conceito de responsabilidade social contemple os deveres que uma organização precisa desempenhar para ser considerada socialmente responsável, abordando, simultaneamente, os seguintes aspectos: 1) econômica, visto que ela é a unidade econômica básica da sociedade; 2) legal, pois a sociedade espera que a organização cumpra com sua missão econômica em conformidade com as exigências legais; 3) ética, devendo as organizações desenvolver suas atividades mediante um comportamento adequado as expectativas da sociedade; 4) discricionária ou filantrópica, uma vez que a sociedade tem expectativas de que as organizações atuem ativamente para a melhoria do ambiente social.

Wood (1991) afirma que a ideia básica da responsabilidade social é que a organização e a sociedade estão entrelaçadas e não são distintas, dessa forma, a sociedade tem expectativas sobre o apropriado comportamento da organização. Para Dahlsrud (2008), a partir do estudo de diversos pesquisadores, o conceito abrange cinco dimensões de responsabilidade social: i) dos públicos de interesse; ii) social; iii) econômica; iv) da voluntariedade; e v) ambiental. Dessas dimensões citadas, apenas duas coincidem com o modelo de Carroll (1979). Além desses autores, outros (Jones 1980; McWilliams \& Siegel 2001; Lea, 2002) definiram responsabilidade social, porém envolvendo as mesmas dimensões, uns contemplando umas e outros contemplando outras.

Desse modo, uma organização socialmente responsável, além de fortalecer seus laços com todas as suas partes interessadas e ganhar legitimidade, também ganha vantagem competitiva e credibilidade, o que acaba lhe acarretando mais facilidade para obter e manter recursos, aumentando seu valor (Fombrun et al., 2000; Milani Filho, 2008; Machado, 2011; Rahin, 2012). Porém, para tanto, é preciso que toda e qualquer organização adote as boas práticas da governança, prestando contas e sendo transparente para com seus stakeholders, inclusive as Oscips, tipo de organização que se define na sequência.

\subsection{Organizações da Sociedade Civil de Interesse Público - Oscip}

As Oscips são um tipo de Organização com Fins Não Econômicos (Ocfne). As Ocfnes são responsáveis por uma parte considerável e crescente da atividade econômica das nações (Hansmann, 1980; Harrison \& Laincz 2008; Wiggill, 2014), elas estão mudando a natureza do 
ambiente econômico (Myers \& Sacks, 2001). Suas atividades envolvem e são limitadas a variados cuidados com a saúde e o bem-estar das pessoas, assim como atividades de educação em geral (Fletcher, et al. 2003). As mesmas têm sido vistas pelos governos como outro meio de prestar serviços públicos e de redistribuição voluntária da riqueza. Elas fornecem produtos e serviços que o governo pode ser convidado a contribuir, na medida em que o mesmo terceiriza o seu trabalho, numa parceria público privada (Carroll \& Steane 2000; Fletcher, et al. 2003; Hofmann \& McSwain, 2013). Como consequência, aumenta a necessidade de confiança do público e do governo nesse tipo de organização (Fletcher, et al. 2003; Spear, Cornforth \& Aiken 2009). Os arranjos de governança das Ocfnes devem ser adequados para assegurar que elas sejam efetivas, responsáveis, cumpridoras de sua missão e prestadoras de contas de suas ações (Cornforth 2012; Fletcher, et al. 2003), o que resulta na necessidade de transparência da gestão (Gray, Bebbington \& Collison, 2006; Zainon, Atan \& Wah, 2014).

Uma característica dessas organizações é que o patrimônio delas é formado a partir das doações de bens e direitos, vindas de qualquer doador social (incluindo os governos e os demais públicos interessados), que não se configuram como proprietários da organização e, portanto, não podem reivindicar retorno sobre o investimento feito (Core, Guay \& Verdi, 2006; Gentry, 2002). Por outro lado, isso não significa que essas organizações não sejam monitoradas. Os doadores, que são os investidores sociais (Hansmann, 1990), dentre outros públicos de interesse, demandam informações, buscando controlar e monitorar a aplicação dos recursos e o cumprimento da missão das organizações (Core, Guay \& Verdi, 2006; Hansmann, 1990).

As Ocfnes, diferentemente das organizações com fins econômicos, são beneficiadas por regras tributárias especiais concedidas pelos governos. Essas regras atingem várias áreas governamentais, desde os encargos relativos à seguridade social até tributação sobre a renda. Os benefícios incluem isenção de impostos, taxas e contribuições, como também vantagens na busca por recursos financeiros junto aos governos, permitindo às organizações fazerem escolhas de financiamento e investimentos que possibilitem a ampliação do retorno social (Gentry, 2002; Hansmann, 1980; 1990). Esses benefícios incluem as Oscips.

Organizações da Sociedade Civil de Interesse Público, ou simplesmente Oscip, é uma qualificação dada às organizações com fins não econômicos que se enquadram nos requisitos da Lei 9.790, de 23 de março de 1999. Essa lei é considerada o marco regulatório do Terceiro Setor no Brasil, pois visa seu crescimento priorizando a transparência, destacando o papel dos conselhos, da auditoria externa e das boas práticas administrativas para reduzir os conflitos de interesse e aumentar a credibilidade nas organizações que compõem esse setor (Ferrarezi \& Rezende, 2002; Serviço Brasileiro de Apoio à Micro e Pequena Empresa [Sebrae], 2009; Machado, 2011).

A Lei 9.790 (1999) relaciona as organizações que podem e não podem qualificar-se como Oscip e as exigências que necessitam ser observadas como, por exemplo, a prestação de contas de todos os valores e bens recebidos de origem pública, a contabilidade (em conformidade com Normas Brasileira de Contabilidade e elaborada de acordo com os princípios contábeis) e a obrigatoriedade de sua publicação em meio eficaz das demonstrações contábeis, além da execução físico-financeira do Termo de Parceria e das receitas e gastos efetivamente realizados (Lei 9.790, 1999; Ferrarezi \& Rezende, 2002; Sebrae, 2009).

Cabe ao Ministério da Justiça conceder a qualificação de Oscip para as organizações, bem como instaurar processo administrativo para perda desta qualificação, permitir o livre acesso do público a todas as informações pertinentes as Oscips e ser o receptor das prestações de contas (Lei 9.790, 1999; Ferrarezi \& Rezende, 2002; Sebrae, 2009).

No que tange a gestão, as organizações qualificadas, como Oscips, deverão ser regidas por princípios e boas práticas de governança, destacando a presença da Assembleia Geral, do Conselho Fiscal e da Gestão Executiva ou Direção Executiva (Lei 9.790, 1999, Sebrae, 2009).

A seguir, apresentam-se os procedimentos metodológicos utilizados para a pesquisa. 


\section{PROCESSO METODOLÓGICO}

Este estudo é uma pesquisa de cunho qualitativo e descritivo (Vergara, 2014), cuja coleta de evidências foi realizada, primeiramente, por meio de pesquisa bibliográfica. Em seguida, ocorreu a pesquisa documental e observação não participante nas páginas eletrônicas de Internet das organizações com fins não econômicos, qualificadas como Oscips. As evidências da pesquisa documental também foram coletadas nos sites de entidades e instituições, tais como Ibgc, Ministério da Justiça, Palácio do Planalto e outros sítios de Internet que possibilitaram consultar documentos relevantes para o alcance do objetivo da pesquisa.

O universo dessa pesquisa foi de 333 organizações que estavam qualificadas como Oscips, no Estado do Rio Grande do Sul, em agosto de 2014. A amostra resulta daquelas que apresentaram informações disponíveis para acesso ao público em geral, por meio de seus sítios de Internet e totalizam 89 Oscips.

Para a pesquisa, primeiramente, fez-se a definição das categorias e dos indicadores para avaliar a prestação de contas e a transparência das Oscips. Essa definição deu-se a partir da revisão da literatura teórica e empírica de autores, tais como Patten (1991); Lindblom (1994); Yusoff, Lehman \& Nasir (2006); Brito, Oliveira, Santos, Luca e Oliveira (2008); Mendes-da-Silva, FerrazAndrade, Famá e Maluf (2009); Soldi, Hatz, Santos e Silva (2007); Murcia e Santos (2009); Cruz (2010); Carneiro, Oliveira, Torres (2011); Rover et al. (2012); Santos Silva e Macagnan (2012); Macêdo, Moura, Dagostini e Hein (2013); Zittei, Politelo e Scarpin (2013); Bezerra, Pereira e Albuquerque (2014); bem como a Lei 9.790 (1999), a NBC T 15 (CFC, 2004), a NBC - ITG 2002 (CFC, 2012) e documentos de orientação de evidenciação, tal como o Global Reporting Iniciate (GRI, 2011). A relação dessas categorias e indicadores está demonstrada na figura 3:

\begin{tabular}{|c|c|}
\hline Demonstrações Financeiras & Ambiental \\
\hline Balanço patrimonial & \multirow{15}{*}{$\begin{array}{l}\text { Política ambiental } \\
\text { Projetos ambientais } \\
\text { Certificações ambientais } \\
\text { Controle de poluição } \\
\text { Preservação e reparo de danos ambientais } \\
\text { Educação ambiental } \\
\text { Parceiras ambientais } \\
\text { Reciclagem } \\
\text { Reflorestamento } \\
\text { Uso eficiente e/ou reutilização da água } \\
\text { Conservação e/ou uso eficiente de energia } \\
\text { Conservação da biodiversidade } \\
\text { Auditoria ambiental } \\
\text { Gastos ambientais } \\
\text { Investimentos ambientais }\end{array}$} \\
\hline Do resultado do exercício (superávit ou déficit) & \\
\hline De mutações do patrimônio líquido & \\
\hline Do fluxo de caixa & \\
\hline Das origens e aplicações de recursos & \\
\hline Notas explicativas & \\
\hline Balanço social - BS & \\
\hline Do valor adicionado - DVA & \\
\hline Parecer Conselho Fiscal & \\
\hline Parecer dos auditores independentes & \\
\hline \multirow{2}{*}{ Relatórios } & \\
\hline & \\
\hline Sobre execução do objeto do termo de parceria & \\
\hline Extrato de relatório de execução física e financeira & \\
\hline Relatório anual de execução de atividade & \\
\hline Certidões Negativas & Social \\
\hline Certidão Negativa do FGTS & \multirow{15}{*}{$\begin{array}{l}\mathrm{N}^{\circ} \text { Funcionários } \\
\text { Perfil dos funcionários } \\
\text { Oportunidade de trabalho } \\
\text { Saúde e segurança no trabalho } \\
\text { Investimento em qualificação profissional } \\
\text { Remuneração } \\
\text { Benefícios } \\
\text { Comunicação } \\
\text { Mecanismos de reclamação } \\
\text { Projetos sociais } \\
\text { Abrangência } \\
\text { Seminários/Eventos } \\
\text { Política de responsabilidade social }\end{array}$} \\
\hline Certidão Negativa do INSS & \\
\hline Estratégica & \\
\hline Histórico & \\
\hline Missão e visão & \\
\hline Princípios e Valores & \\
\hline Objetivos & \\
\hline Planos e metas & \\
\hline Investimentos & \\
\hline Governança e sistema organizacional & \\
\hline Organograma & \\
\hline Estrutura organizacional & \\
\hline Estrutura física & \\
\hline Atividades & \\
\hline Estatuto & \\
\hline
\end{tabular}

Revista de Gestão Social e Ambiental - RGSA, São Paulo, v. 9, n. 3, p. 24-44, set./dez., 2015. 


\section{Auditoria interna \\ Auditoria independente \\ Contador responsável \\ Composição dos conselhos \\ Identificação dos dirigentes \\ Remuneração dos dirigentes \\ Presença de comitês}

Figura 3: Categorias e indicadores de transparência

Fonte: Adaptado dos autores citados no parágrafo anterior.

Após a definição das categorias e indicadores, fez-se o levantamento das evidências junto aos sites das Oscips que tinham página de internet. Para este levantamento, utilizou-se de uma planilha Excel onde foram postas todas as organizações, todas as categorias e todos os indicadores identificados na revisão da literatura.

Por meio de análise de conteúdo que, segundo Bardin (1977), se trata de um conjunto de técnicas de análise de comunicações que, por intermédio de procedimentos sistemáticos e objetivos de descrição do conteúdo, possibilita a inferência de conhecimentos relativos às variáveis inferidas das mensagens e iniciou-se o tratamento das evidências. Nesta etapa, foi definido se a informação estava ou não evidenciada. Para a informação evidenciada, atribuiu-se peso um e para a informação não evidenciada, peso zero. Depois, foi feita a soma dos indicadores evidenciados e calculado o percentual de evidenciação por Oscip.

A pesquisa teve limitações, uma vez que se fez uso apenas de informações disponíveis no meio eletrônico não havendo o acesso as evidências restritas às dependências das organizações e a seus membros, assim como não se verificou a veracidade das informações divulgadas e não foi analisado o grau de importância dessas informações. Também não foi analisado porque as demais organizações do universo da pesquisa não divulgam suas informações por meio de páginas de Internet.

\section{APRESENTAÇÃO E DISCUSSÃO DOS RESULTADOS}

Inicia-se a apresentação dos resultados pelos indicadores encontrados nos sítios de internet das Oscips, que foram 28 dos 62 possíveis, o que representa 45,17\% das informações esperadas, prestadas aos stakeholders por meio desta ferramenta de comunicação. $\mathrm{Na}$ maior parte das organizações foi encontrado entre 7 a 12 indicadores de transparência, ou seja, de 11,30\% a 19,35\% do total de informações voluntárias que, à luz da governança, podem ser usadas como prestação de contas.

Na figura 4, são apresentados os resultados dos indicadores por categoria:

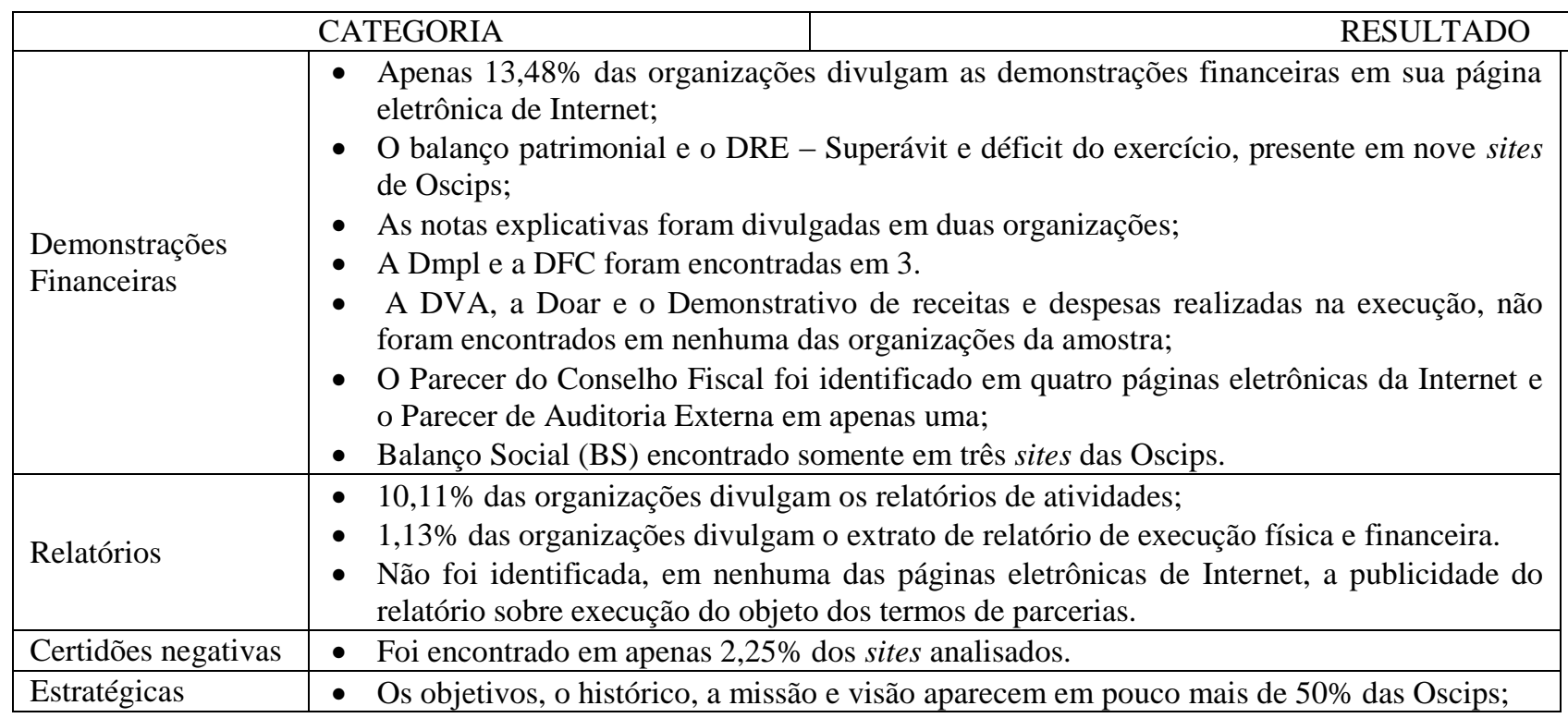

Revista de Gestão Social e Ambiental - RGSA, São Paulo, v. 9, n. 3, p. 24-44, set./dez., 2015. 


\begin{tabular}{|c|c|}
\hline & $\begin{array}{l}\text { - Planos e metas foram encontrados em quatro organizações, e investimentos em apenas } \\
\text { duas. }\end{array}$ \\
\hline $\begin{array}{l}\text { Governança e } \\
\text { sistema } \\
\text { organizacional }\end{array}$ & $\begin{array}{l}\text { - } 86 \text { Oscips buscaram divulgar as atividades desenvolvidas; } \\
\text { - A estrutura organizacional e a identificação dos dirigentes constam em } 59 \text { páginas; } \\
\text { - O estatuto foi localizado em } 18 \text { organizações; } \\
\text { - O nome do contador responsável aparece em } 12 \text { sites; } \\
\text { - Estrutura física e organograma foram mencionados em seis e três páginas, } \\
\text { respectivamente; } \\
\text { - Auditoria interna e remuneração dos dirigentes não foram encontradas em nenhuma das } \\
\text { páginas eletrônicas; } \\
\text { - A presença de auditoria externa foi evidenciada em duas organizações, embora só uma } \\
\text { delas tenha divulgado o parecer de auditoria; } \\
\text { - Em três Oscips foram encontradas a existência de Comitê (Técnico, Científico e } \\
\text { Financeiro); } \\
\text { - Os Conselhos (Administrativo, Fiscal e Consultivo) obtêm maior presença na composição } \\
\text { estrutural das organizações, tendo sido destacadas em } 47 \text { sites. }\end{array}$ \\
\hline Ambiental & $\begin{array}{l}\text { - } 27 \text { Oscips divulgam sua política ambiental e seus projetos ambientais; } \\
\text { - Os indicadores reflorestamento, auditoria ambiental, gastos ambientais e investimentos } \\
\text { ambientais não foram identificados em nenhuma das páginas analisadas; } \\
\text { - Apenas um divulgou informações sobre uso eficiente da água e da energia; } \\
\text { - Controle de poluição e parcerias ambientais foram evidenciadas em cinco organizações; } \\
\text { - Somente três Oscips apresentaram certificações ambientais; } \\
\text { - } 17 \text { organizações mencionam atividades de educação ambiental; } \\
\text { - Preservação e reparo de danos ambiental foram destacados por } 9 \text { Oscips; } \\
\text { - Já a reciclagem foi mencionada por } 17 \text { organizações. }\end{array}$ \\
\hline Social & 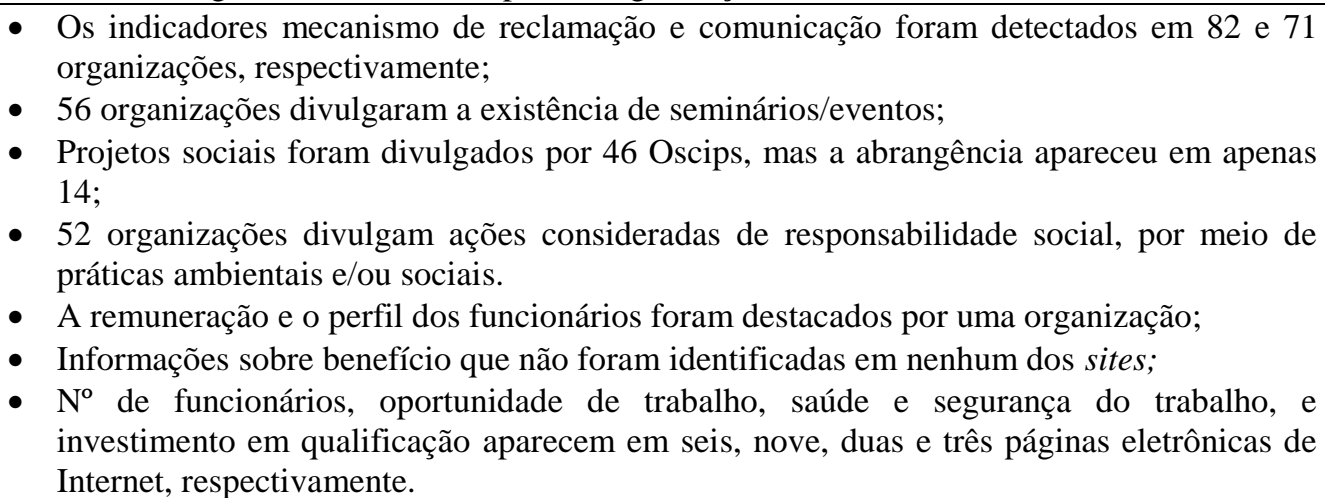 \\
\hline
\end{tabular}

Figura 4: Indicadores evidenciados

Fonte: Elaborado pelas autoras

Os resultados apresentados corroboram com os autores Soldi et al. (2007), Carneiro et al. (2011), Zittei et al. (2013), Bezerra et al. (2014), dentre outros que, por meio de pesquisas empíricas, constataram a falta de transparência e prestação de contas das Oscips que deixam de divulgar informações que interessam a todos os stakeholders, principalmente aos externos. Estudos em outras organizações do terceiro setor também salientam a falta de transparência e prestação de contas das organizações (Hofmann \& McSwain, 2013; Seibert \& Macagnan, 2015).

A Lei 9.790 (1999) determina que as Oscips deem publicidade para seus relatórios, deixando-os a disposição de qualquer cidadão. No entanto, a obrigação, de fato, é que os demonstrativos contábeis devem ser enviados ao Ministério da Justiça (Lei 9.790, 1999), por meio do seu Portal, não havendo outra exigência de evidenciação, como nas páginas de internet, por exemplo. A pesquisa demonstrou que somente $11,24 \%$ das organizações da amostra estão divulgando suas demonstrações contábeis nos seus sites. Essa porcentagem corrobora a constatação de Cruz (2010) de que não é praxe dessas organizações divulgar suas demonstrações contábeis, mesmo que o Balanço Patrimonial e o Demonstrativo do Resultado do Exercício sejam os mais utilizados para divulgação de informações financeiras (Bezerra et al., 2014; Duff, 2014). 
Outro demonstrativo com escassez de publicidade foi ao Balanço Social (BS), elucidando que as três organizações que externaram esse demonstrativo não estão entre as nove que divulgaram o Balanço Patrimonial. Cabe enfatizar a utilidade do Balanço Social como instrumento propício a dar maior visibilidade e credibilidade às atividades executadas pelas Oscips. Ele demonstraria a realização dos trabalhos sociais, bem como as ações relativas ao meio ambiente contribuindo para a legitimação das organizações na comunidade onde estão inseridas (Melo \& Froes, 2001; Brito et al., 2008; Milani Filho, 2008; Beuren, Hein \& Boff, 2011; Santos Silva \& Macagnan, 2012; Bezerra et al., 2014).

O baixo número de evidenciação dos demonstrativos contábeis e dos relatórios pressupõe a ausência de interesse das organizações em prestar contas para os stakeholders (Harrison, Rouse \& Villiers, 2012; Williams \& Adams, 2013; Araújo Junior, et al., 2014; Park, Chidlou \& Choi, 2014; Pérez \& Bosque, 2015). Além disso, também demonstra a divergência na forma de prestação de contas aos diversos interessados nessas informações (Soldi et al., 2007; Berreza et al., 2014), pois não permitem acesso facilitado aos financiadores, doadores e público em geral. Salienta-se que mesmo desobrigadas dessa evidenciação nas páginas de internet, tais documentos e relatórios são importantes para sustentabilidade e legitimação das organizações (O'Donovan, 2002; O'Dwyer, 2003; Duff, 2014; Seibert \& Macagnan, 2015). As organizações devem considerar o poder dos stakeholders para formar grupos de pressão contra a organização quando identificam que o contrato social pré-estabelecido está ameaçado (Lindblom, 1994; Suchman, 1995; O’Donovan, 2002; Pérez \& Bosque, 2015).

Outro fator que merece destaque se refere as informações desatualizadas encontradas em seis das organizações que publicaram indicadores da categoria Demonstrações Financeiras, o que prejudica a análise dessas informações (Soldi et al., 2007) e, consequentemente, pode gerar desconfiança por parte dos stakeholders na credibilidade da organização (Michelon, 2011; Michelon \& Parbonetti, 2012).

A exigência legal de divulgação se estende as Certidões Negativas de Débito do INSS e do FGTS (Lei 9.790, 1999), todavia, os indicadores dessa categoria foram pouco evidenciados. Essa situação além de reduzir a transparência dessas organizações, ratifica a constatação de Bezerra et al. (2014) que afirmam que a maioria delas não executa o que a lei preconiza. Neste contexto, cabe destacar que as organizações que não cumprem a legislação podem sofrer punições legais, tal como perda de benefícios fiscais (Watts \& Zimmerman, 1978; Dye, 1986; Wagenhofer, 1990).

A categoria estratégica teve todos os seus indicadores identificados nas páginas eletrônicas de Internet observadas, demonstrando haver a preocupação em deixar claro para os públicos a orientação geral da organização e suas metas sociais. Essa constatação é positiva, pois os elementos evidenciados são componentes essenciais da administração estratégica que proporciona ao stakeholders avaliar as necessidades dessas instituições, os recursos que elas precisam para satisfazer essas necessidades e, por fim, monitorar se os resultados estão de acordo com o que foi proposto (Hudson, 1999). Também demonstra que as organizações estão fazendo a gestão da evidenciação, no sentido de buscar o apoio dos doadores para a sua causa social (Fletcher, et al. 2003; Gray, Bebbington \& Collison, 2006; Cornforth 2012; Zainon, Atan \& Wah, 2014; Mzembe \& Downs, 2014; Park, Chidlow, \& Choi, 2014).

$\mathrm{Na}$ categoria governança e sistema organizacional, os indicadores mais identificados referem-se ao sistema organizacional. Os indicadores de Governança remetem aos mecanismos de controle interno que as organizações devem ter para reduzir os conflitos de interesse entre os gestores, investidores sociais e governo, bem como a assimetria informacional existente entre as partes interessadas (Slomski et al., 2008; IBGC, 2009; Machado, 2011). No entanto, notou-se a ausência da evidenciação desses mecanismos em parte dos sites observados, inclusive dos exigidos legalmente, como é o caso do Conselho Fiscal. Olak e Nascimento (2010) apontam a importância do Conselho Fiscal e seu parecer, por examinar as contas da administração (Lei 9.790, 1999; Sebrae, 2009) assim como a importância do parecer da Auditoria Externa que atesta a veracidade das demonstrações contábeis, gerando a credibilidade no trabalho desenvolvido pelas organizações.

Revista de Gestão Social e Ambiental - RGSA, São Paulo, v. 9, n. 3, p. 24-44, set./dez., 2015. 
O fato de as Oscips não divulgarem esses mecanismos em suas páginas eletrônicas não configura a falta deles na organização, porém demonstra o baixo nível de transparência delas, o que pode prejudicar a sua legitimidade e, portanto, permanência na comunidade onde está inserida (Patten, 1991; Lindblom, 1994; Suchman, 1995; Deegan, Rankin, \& Tobin, 2002; O’Donovan, 2002; Williams \& Adams, 2013).

$\mathrm{Na}$ categoria ambiental, os indicadores mais evidenciados foram política ambiental e projetos ambientais, confirmando os resultados encontrados nas pesquisas de Yusoff, Lehman \& Nasir (2006) e Macedo et al. (2013). No entanto, a evidenciação desses indicadores não atinge 50\% das organizações. Diante disso, torna-se notória a insuficiência de informações divulgadas relativas as ações ambientais executadas pelas Oscips, fator este que destaca a necessidade de crescimento do nível da transparência ambiental por parte das organizações, principalmente pela importância do tema no momento (Burritt, 2012; Hassan \& Burgess, 2012; Macedo et al.,2013; Mota, Mazza, \& Oliveira, 2013).

Alguns indicadores que compõem a categoria social foram assiduamente evidenciados nos sítios de Internet das Oscips e, em razão disto, esta categoria se sobressaiu perante as demais como a mais evidenciada. Essa evidenciação confirma a gestão da evidenciação em torno do fim social da organização no sentido de buscar o apoio dos doadores para a sua causa (Fletcher, et al. 2003; Gray, Bebbington \& Collison, 2006; Cornforth 2012; Zainon, Atan \& Wah, 2014). Por outro lado, os indicadores alusivos ao funcionamento interno das organizações aparecem menos evidenciados, como é o caso de remuneração, perfil dos funcionários e informações sobre benefícios, não identificados em nenhum site. A falta de evidenciação desses indicadores confirma a gestão da evidenciação das organizações no sentido de não evidenciar questões que podem gerar conflitos com seus públicos de interesse e lhes tirar vantagem competitiva (Watts \& Zimmerman, 1978; Dye, 1986; Wagenhofer, 1990).

Cabe destacar que a desarmonia entre os níveis de divulgação de informações internas e externas transparece que as organizações não desenvolvem igualmente os dois âmbitos sociais, por exemplo, elas realizam projetos sociais em prol da sociedade, mas podem não disponibilizar benefícios para seus funcionários. Deste modo, essa análise corrobora com Melo e Froes (2001) ao alegar que nem sempre as organizações são atuantes e eficazes nas duas dimensões sociais, tornando parcial a envoltura e o engajamento social da organização (Milani Filho, 2008). Também, reforça a afirmação de Yussof, Lehman \& Nasir (2006) que as organizações precisam considerar todos os seus stakeholders, e não beneficiar um grupo em detrimento dos outros.

O indicador política de responsabilidade social foi analisado considerando a divulgação dos indicadores de políticas ambientais, projetos ambientais e projetos sociais. As evidências levantadas demonstram que 52 Oscips divulgam ações consideradas de responsabilidade social, por meio de práticas ambientais e/ou sociais. Para corresponder às expectativas sociais, as Oscips deveriam evidenciar esses indicadores, pois, conforme preconizam as teorias sociais (Carroll, 1979; Fombrun et al., 2000; Melo \& Froes, 2001; Machado, 2011; Rahin, 2012), uma organização socialmente responsável executa suas ações não só em conformidade com as exigências legais, mas considerando seu público interno, a sociedade em geral, o desenvolvimento socioeconômico e o meio ambiente, ou seja, todos os seus stakeholders (Freeman \& McVea, 2001; Freeman, 2002; Phillips, 2003; Parmar, et al., 2010; Machado, 2011). Assim, mantém uma relação equilibrada com todos, garantindo, recuperando ou ampliando a sua legitimidade (Suchman, 1995).

Frisa-se que a ausência de divulgação das informações usadas na pesquisa como indicadores de transparência e de prestação de contas, não denota a inexistência delas nas organizações, mas ratifica os estudos anteriores que também encontraram falta de transparência (Assis et al., 2006; Yusoff, Lehman \& Nasir, 2006; Soldi et al., 2007; Brito et al., 2008; Milani Filho, 2008; Gimenes, 2010; Carneiro et al., 2011; Macedo et al., 2013; Bezerra et al., 2014). Além disso, a baixa evidenciação observada demonstra a necessidade de melhoria no sistema de governança, incluindo os princípios de transparência, de prestação de contas e da responsabilidade social organizacional. 
Destaca-se também que a falta de transparência e prestação de contas pode punir as organizações com perdas de benefícios fiscais, reputação, credibilidade e legitimidade, prejudicando a permanência delas na comunidade onde estão inseridas (Watts \& Zimmerman, 1978; Dye, 1986; Wagenhofer, 1990; Lindblom, 1994; Suchman, 1995; O’Donovan, 2002; Michelon, 2011; Seibert \& Macagnan, 2015).

\section{CONSIDERAÇÕES FINAIS}

Durante a pesquisa, foi possível perceber que as páginas eletrônicas das Oscips são frequentemente usadas para divulgar fins diversos. Por outro lado, a evidenciação, nos sites das Oscips, de informações para prestação de contas dos recursos angariados e sua aplicação, a abrangência e os resultados obtidos das atividades desenvolvidas, o envolvimento e o cumprimento socialmente responsável dessas organizações, é insuficiente para a formação de opinião dos seus stakeholders e garantir a legitimidade organizacional. Essa constatação é reforçada pelo total dos indicadores encontrados durante a pesquisa, dos 62 indicadores somente 28 foram localizados. Porém, esse total foi encontrado em apenas uma Oscip das 89 Oscips investigadas, a maioria divulgou entre 7 e 12 indicadores de transparência previamente identificados na revisão de literatura.

As categorias mais evidenciadas foram a social e a de governança, encontradas em 97,75\% e 95,51\% das páginas eletrônicas de Internet analisadas, respectivamente. No entanto, os indicadores direcionados ao atendimento do público externo são mais divulgados do que aqueles que remetem ao público interno das Oscips, em ambas as categorias. Já os indicadores da categoria estratégia foram todos evidenciados, mesmo que dois deles tenham sido informados apenas por algumas das Oscips. Os resultados demonstram a preocupação das organizações em elucidar seus componentes estratégicos, dando a possibilidade aos stakeholders de monitorar e avaliar se as ações desenvolvidas estão de acordo com os seus interesses (Freeman \& McVea, 2001; Freeman, 2002; Phillips, 2003; Parmar, et al., 2010; Machado, 2011). Demonstram também a gestão da evidenciação das organizações, tanto para valorizar a sua missão social, como para se prevenir de possíveis punições, tal como a perda de benefícios fiscais, de reputação, credibilidade e legitimidade, que poderiam prejudicar a sua permanência na comunidade onde estão inseridas (Watts \& Zimmerman, 1978; Dye, 1986; Wagenhofer, 1990; Fletcher, et al. 2003; Gray, Bebbington \& Collison, 2006; Cornforth 2012; Michelon, 2011; Zainon, Atan \& Wah, 2014; Seibert \& Macagnan, 2015).

As categorias com baixos níveis de divulgação são a certidão negativa (2,25\%), relatórios $(11,24 \%)$ e demonstrações financeiras $(13,48 \%)$, salientando-se que grande parte das informações pertencentes a essas categorias são obrigatórias para prestação de contas com o Ministério da Justiça. Bezerra et al., 2014; Cruz, 2010; Soldi et al., 2007 já haviam constatado a existência de divergências na prestação de contas e a falta de habitualidade dessas organizações em divulgar suas informações financeiras, além de detectar que muitas não atendem plenamente ao que preconiza a lei. Neste contexto, as Oscips estariam demonstrando a sua fragilidade na prestação de contas para com seus stakeholders e correndo riscos contra a sua legitimidade e direito de permanecer atuando na comunidade onde estão inseridas (Lindblom, 1994; Suchman, 1995; Salamon, 1997; Hudson, 1999; Coelho, 2000; O’Donovan, 2002; Leal \& Famá, 2007).

Comparada às demais, a categoria ambiental obteve uma posição mediana ao ser evidenciada em 30,34\% dos sites de Internet das Oscips, o que ratifica pesquisas anteriores (Macedo et al., 2013; Yusoff, Lehman \& Nasir, 2006). No entanto, o número de indicadores ambientais identificados durante a pesquisa demonstra a necessidade de as organizações aumentarem o nível de transparência ambiental, pois mesmo que não exerçam impacto ambiental, a sua performance é avaliada pelos seus stakeholders para a legitimação da organização (Murcia \& Santos, 2009; Burritt, 2012; Macedo et al., 2013; Marquezan, et al., 2015).

Assim, mediante o que foi exposto, considera-se que a questão da pesquisa foi respondida e o objetivo principal foi alcançado, uma vez que se identificou quais são as informações 
disponibilizadas pelas Oscips do Estado do Rio Grande do Sul como prestação de contas aos seus públicos de interesse, por meio de suas páginas eletrônicas da Internet. Por meio dos resultados da pesquisa, foi possível verificar que as Oscips ainda têm muito a evoluir para atender aos princípios e pressupostos da governança das organizações, de forma a garantir um relacionamento harmonioso com todos os seus stakeholders para assegurar a sua reputação, credibilidade e legitimidade, concedido pelo poder dos seus stakeholders, garantindo o direito de permanência na comunidade onde estão inseridas.

Por fim, cabe frisar que este artigo não tem a pretensão de esgotar a discussão sobre o tema, por isso, anseia-se por novas investigações abordando outras questões que possam contribuir para ampliar o conhecimento e a melhoria do sistema de governança das organizações caracterizadas como Oscips.

\section{REFERÊNCIAS}

AccountAbility. (2008) AA1000 Accountability Principles Standard. Recuperado em: 23 de 09 de 2015, de: www.accountability.org/standards/aa1000aps.html.

Alchian, A., Demsetz, A. (1972) Production, information costs, \& economic organization. The American Ecomonic Review, 777 - 795.

Álvarez, I. G., Sánchez, I. M. G., \& Domínguez, L. R. (2008) Voluntary \& compulsory information discloses online: the effect of industry concentration \& other explanatory factors. Online Information Review, 32(5), 596-622.

Araújo Junior, J., Oliveira, M., Ponte, V., \& Ribeiro, M. (2014) Social disclosure of brazilian and uk firms in light of stakeholder theory, legitimacy theory and voluntary disclosure theory. Advances in Scientific and Applied Accounting, 7(2), 175-200.

Ashley, P., Coutinho, R., \& Tomei, P. (2000) Responsabilidade social corporativa e cidadania empresarial: uma análise conceitual comparativa. Anais Enampad. Florianópolis, Setembro.

Assis, M. S., Mello, G. R., \& Slomski, V. (2006) Transparência nas entidades do Terceiro Setor: a demonstração do resultado econômico como instrumento de mensuração do desempenho. Anais do Congresso USP de Iniciação Científica em Contabilidade, São Paulo, Brasil, 3.

Avelino, B. C., Pinheiro, L. E., \& Lamounier, W. M. (2012) Evidenciação de ativos intangíveis: estudo empirico em companhias abertas. Revista de Contabilidade e Organizações, 6(14), 22-45.

Bardin, L. (1977) Análise de conteúdo. São Paulo: Edições 70.

Berle, A. A., \& Means, G. C. (1932) A moderna sociedade anônima e a propriedade privada (2a ed.). São Paulo: Nova Cultural.

Beuren, I. M., \& Sothe, A. (2009) A teoria da legitimidade e o custo político nas evidenciações contábeis dos governos estaduais da região sudeste do Brasil. RCO - Revista de Contabilidade e Organizações, 3(5), 98-120.

Beuren, I. M., Hein, N., \& Boff, M. L. (2011) Estratégias de legitimidade organizacional de Lindblom versus geração familiar gestora de empresas familiares. Revistas Iberoamericana de Contabilidad de Gestion - RIGC, 9(17). 
Bezerra, E. S., Pereira, M. de L., \& Albuquerque, L. S. (2014) Um estudo nas demonstrações contábeis elaboradas, divulgadas e utilizadas na prestação de contas das Organizações da Sociedade Civil de Interesse Público - Oscip do Brasil. Anais do Congresso Brasileiro de Custos, Natal, RN, Brasil, 11.

Brasil, Lei n. 9.790, de 23 de março de 1999 (1999) Dispõe sobre a qualificação de pessoas jurídicas de direito privado, sem fins lucrativos, como Organizações da Sociedade Civil de Interesse Público, institui e disciplina o Termo de Parceria, e dá outras providências. Recuperado em 24 julho, 2014, de http://www.planalto.gov.br/ccivil_03/leis/19790.htm.

Brito, P. P., Oliveira, M. C., Santos, S. M. dos, \& Oliveira, B. C. de. (2008) A utilização dos demonstrativos contábeis como instrumento de apoio a gestão nas organizações não governamentais: um estudo de caso no estado do Ceará. Revista Alcance, 15(1), 61 - 80.

Burritt, R. (2012) Environmental performance accountability: planet, people, profits. Accounting, Auditing \& Accountability Journal, 25 (2), 370-405.

Carneiro, A. de F., Oliveira, D. de L., \& Torres, L. C. (2011) Accountability e prestação de contas das organizações do terceiro setor: uma abordagem à relevância da contabilidade. Sociedade, Contabilidade e Gestão, Rio de Janeiro, 6(2), 90-105.

Carroll, A. B. (1979) A three-dimensional conceptual model of corporate performance. Academy of Management Review, 4(4), 497-505.

Carroll, A. B. (1999). Corporate social responsibility: evolution of a definitional construct. Business \& Society, 38(3), 268-295.

Carroll, P., \& Steane, P. (2000) Public private partnerships: sectoral perspectives. Em S. Osborne, Public-Private partnerships for public services: an international perspective, 36-56). London: Routledge.

Cho, C. H., Freedman, M., \& Patten, D. M. (2012) Corporate disclosure of environmental capital expenditures: a test of alternatives theories. Accounting, auditing \& accountability Journal, 25(3), 486-507.

Coase, R. (1937) The nature of the firm. Econômica, 4(16), 386 - 405.

Coelho, S. C. T. (2000) Terceiro setor: um estudo comparativo entre Brasil e Estados Unidos. São Paulo: Senac.

Conselho Federal de Contabilidade (CFC, 2004) NBC - T 15 - Informações de natureza social e ambiental.

Conselho Federal de Contabilidade (CFC, 2012) NBC - ITG 2002 - Entidade sem finalidade de lucro.

Core, J. E., Guay, W. R., \& Verdi, R. S. (2006) Agency problems of excess endowment holdings in not-for-profit firms. Journal of Accounting and Economics, 41(3), 307-333.

Cornforth, C. (2012) Nonprofit governance research: Limitações of the focus on boards and suggestions for new directions. Nonprofit and Voluntary Sector Quarterly, 41(6), 1117-1136. 
Cruz, C. V. O. A. (2010) A relevância da informação contábil para os investidores sociais privados de entidades do terceiro setor no Brasil: uma investigação empírica. Tese de Doutorado, Universidade de São Paulo, São Paulo, SP, Brasil.

Cunha, J., Frankenberger, F., Povoa, A., \& Silva, W. (2015) Disclosure socioambiental e o impacto no custo de capital. Revista ADMpg Gestão Estratégica, 8(2), 55-63.

Dahlsrud, A. (2008) How corporate social responsibility is defined: an analysis of 37 definitions. Corporate Social Responsibility and Environmental Management, 15, 1-13.

Dantas, J. A., Zendersky, H. C., \& Niyama, J. K. (2004) A dualidade entre os benefícios do disclosure e a relutância das organizações em aumentar o grau de evidenciação. Anais do Encontro da Associação Nacional de Pós-Graduação e Pesquisa em Administração, Curitiba, PR, Brasil, 28.

Dechow, P., Ge, W., \& Schrand, C. (2010) Understanding earnings quality: a review of the proxies, their determinants and their consequences. Journal of Accounting and Economics, 50, 344-401.

Deegan, C., Rankin, M., \& Tobin, J. (2002) An examination of the corporate social \& environmental disclosures of BHP from 1983-1997: a test of legitimacy theory. Accounting, Auditing \& Accountability Journal, 15(3), 312 - 343.

Drobetz, W., Merikas, A., Merika, A., \& Tsionas, M. (2014) Corporate social responsibility disclosure: The case of international shipping. Transportation Research Part E, 71, 18-44.

Duff, A. (2014) Corporate social responsibility reporting in professional accounting firms. The British Accounting Review, 1-13.

Dye, R. A. (1986) Proprietary and nonproprietary disclosures. The Journal of Business, 59(2), 331366.

Ferrarezi, E., \& Rezende, V. (2002) Oscip - Organização da sociedade civil de interesse público: a lei 9.790/99 como alternativa para o terceiro setor (2a ed.). Brasília: Comunidade Solidária.

Fletcher, A., Guthrie, J., Steane, P., Roos, G., \& Pike, S. (2003) Mapping stakeholder perceptions for a third sector organization. Journal of Intellectual Capital, 3, 505-527.

Fombrun, C. J., Gardberg, N. A., \& Barnett, M. L. (2000) Opportunity platforms \& safety nets: corporate citizenship \& reputational risk. Business \& Society Review, 105(1), 85-106.

Freeman, E. R. (2002) Stakeholder theory of the modern corporation.

Freeman, E. R., \& McVea, J. (2001) A stakeholder approach to strategic management. Social Science Research Network.

Gentry, W. M. (2002) Debt, investment and endowment accumulation: the case of not-for-profit hospitals. Journal of Health Economics, 21, 845-872.

Gimenes, É. R. (2010) Transparência na prestação de contas por organizações do Terceiro Setor. Revista Urutágua Acadêmica Multidisciplinar DCS/UEM, 20, 130-140. 
Global Reporting Iniciative. (GRI, 2011) Diretrizes para relatório de sustentabilidade.

Gray, R. (2002) The social accounting project and accounting organizations and society: privileging engagement, imaginings, new accountings and pragmatism over critique? Accounting, Organizations and Society, 27, 687-708.

Gray, R., Bebbington, J., \& Collison, D. (2006) NGOs, civil society and accountability: making the people accountable to capital. Accounting, Audititng \& Accountability Journal, 19(6), 319-348.

Hansmann, H. B. (1980) The role of nonprofit enterprise. The Yale Law Journal, 89(5), 835-902.

Hansmann, H. B. (1990) Why do universities have endowments? The Journal of Legal Studies, 19(1), 03-42.

Harrison, J. A., Rouse, P., \& Villiers, C. J. (2012) Accountability and performance measurement: a Stakeholder perspective. The Business and Economics Research Journal, 5(2), 243-258.

Harrison, T. D., \& Laincz, C. A. (2008) Entry and exit in the nonprofit sector. The B.E. Journal of Economic Analysis \& Policy, (online).

Hassan, A., \& Burgess, S. (2012) The effects of level of disclosure of environmental activities and stakeholders' engagement on achieving bitc awards: an empirical study of UK FTSE 100.

International Journal of Business and Social Science, 2(17) 79-91.

Hofmann, M. A., \& McSwain, D. (2013) Financial disclosure management in the nonprofit sector: a framework for past and future research. Journal of Accounting Literature, 32, 61-87.

Hrasky, S. (2012) Carbon footprints and legitimation strategies: symbolism or action? Accounting, Audititng \& Accontability Journal, 5(1), 174-198.

Hudson, M. (1999) Administrando organizações do terceiro setor: o desafio de administrar sem receita. São Paulo: Makron Books.

Instituto Brasileiro de Governança Corporativa - IBGC, \& Grupo de Institutos Fundações e Empresas. (2014) Guia das melhores práticas de governança para Institutos e Fundações Empresariais. (2a ed.). São Paulo: IBGC; GIFE.

Instituto Brasileiro de Governança Corporativa - IBGC. (2009) Código das melhores práticas de governança corporativa.

Jensen, M., \& Meckling, W. (1976).Theory of the firm: managerial behavior, agency cost, \& ownership structure. Journal of Financial Economics, 3(4), 305-360.

Jo, H., Song, M., \& Tsang, A. (2015) Corporate social responsibility and stakeholder governance around the world. Global Finance Journal, In press, 1-28.

Johansen, T., \& Nielsen, A. (2012) CSR in corporate self-storying - legitimacy as a question of differentiation and conformity. Corporate communications: an international journal, 17(4), 434448. 
Jones, T. M. (1980) Corporate social responsibility revisited, redefined. California Management Review, 22(2), 59-67.

Lambell, R., Ramia, G., Nyland, C., \& Michelotti, M. (2008) NGOs and international business research: progress, prospects and problems. International Journal of Management Reviews, 10(1), 75-92.

Lanis, R., \& Richardson, G. (2013) Corporate social responsibility and tax aggressiveness: a test of legitimacy theory. Accounting, Audititng \& Accountability Journal, 26(1), 75-100.

Lea, R. (2002) Corporate social responsibility, institute of directors (IoD) member opinion survey. London: Published by the Institute of Directors.

Leal, E. A., \& Famá, R. (2007) Governança nas organizações do terceiro setor: um estudo de caso. Anais Seminários em Administração, 10. São Paulo, Brasil.

Lindblom, C. (1994) The implications of organizational legitimacy for corporate social performance \& disclosure.

Lys, T., Naughton, J., \& Wang, C. (2015) Signaling through corporate accountability reporting. Journal of Accounting and Economics, 60, 56-72.

Macêdo, F. F. R. R., Moura, G. D. de, Dagostini, L., \& Hein, N. (2013) Evidenciação ambiental voluntária e as práticas de governança corporativa de empresas listadas na Bm\&Fbovespa. Contabilidade, Gestão e Governança, Brasília, 16(1), 3-18.

Machado, C. P., Filho. (2011) Responsabilidade social e governança: o debate e as implicações (reimp. 1a ed., 2006). São Paulo: Cengage Learning.

Marquezan, L., Seibert, R., Bartz, D., Barbosa, M., \& Alves, T. (2015) Análise dos determinantes do disclosure verde em relatórios anuais de empresas listadas na BM\&FBovespa. Contabilidade, Gestão e Governança, 18(1), 127-150.

McDonnell, B. H. (2011) Strategies for an employee role in corporate governance. Wake Forest Law Review, 46, 429$445,2011$.

McWilliams, A., \& Siegel, D. (2001) Corporate social responsibility: a theory of the firm perspective. Academy ol Management Review, 26(1), 117-127.

Melo, F. P. de, Neto, \& Froes, C. (2001) Responsabilidade social e cidadania empresarial: a administração do terceiro setor (2a ed.). Rio de Janeiro: Qualitymark.

Mendes-da-Silva, W., Ferraz-Andrade, J. M., Famá, R., \& Maluf, J. A., Filho. (2009) Disclosure via website corporativo: um exame de informações financeiras e de governança no mercado brasileiro. RAE - Revista de Administração de Empresas, São Paulo, 49(2), 190-205.

Michelon, G. (2011) Sustainability disclosure and reputation: a comparative study. Corporate Reputation Review, 14(2), 79-96.

Michelon, G., \& Parbonetti, A. (2012) The effect of corporate governance on sustainability disclosure. Journal Management Governance, 477-509. 
Milani, M. A. F., Filho. (2008) Responsabilidade social e investimento social privado: entre o discurso e a evidenciação. Revista Contabilidade e Finanças, 19(47), 89-101.

Momin, M. A., \& Parker, L. D. (2013) Motivations for corporate social responsibility reporting by MNC subsidiaries in an emerging country: The case of Bangladesh. The British Accounting Review, $45,1-14$.

Mota, M., Mazza, A., \& Oliveira, F. (2013) Uma análise dos relatórios de sustentabilidade no âmbito ambiental do Brasil: sustentabilidade ou camuflagem. Revista de Administração e Contabilidade da Unisinos, 10(1), 69-80.

Murcia, F. D., \& Santos, A. (2009) Fatores determinantes do nível de disclosure voluntário das companhias abertas no Brasil. REPeC - Revista de Educação e Pesquisa em Contabilidade, Brasília, 3(2), 72-95.

Myers, J., \& Sacks, R. (2001) Harnessing the talents of a loose and baggy monster. Journal of European Industrial Training, 25(9), 454-464.

Mzembe, A., \& Downs, Y. (2014) Managerial and stakeholder perceptions of an Africa-based multinational mining company's Corporate Social Responsibility (CSR). The Extractive Industries and Society, 1, 225-236.

O’Donovan, G. (2002) Environmental disclosures in annual report. Extending the applicability \& predictive power of legitimacy theory. Accounting, Auditing \& Accountability Journal. 15(3), 344371.

O'Dwyer, B. (2003) Conceptions of corporate social responsibility: the nature of managerial capture. Accounting, Audititng \& Accountability Journal, 16(4), 523-557.

Olak, P. A., \& Nascimento, D. T. do. (2010) Contabilidade para entidades sem fins lucrativos (terceiro setor) (3. ed.). São Paulo: Atlas.

Organization for Co-operation and Development. (OCDE , 2004) Principles of corporate governance. OECD Publications Service, Paris, France.

Park, B., Chidlow, A., \& Choi, J. (2014) Corporate social responsibility: stakeholders influence on MNEs' activities. International Business Review, 23(5), 966-980.

Parmar, B. L., Freeman, R. E., Harrison, J. S., Wicks, A. C., Purnell, L., \& Colle, S. de. (2010)

Stakeholder theory: the state of the art. The academy of management annals, 4(1), 403-445.

Patten, D. M. (1991) Exposure, legitimacy \& social disclosure. Journal of Accounting \& Public Policy, 10, 297-308.

Pérez, A., \& Bosque, I. (2015) How customers construct corporate social responsibility images: Testing the moderating role of demographic characteristics. BRQ Business Research Quarterly, 18, 127-141.

Phillips, R. (2003) Stakeholder legitimacy. Business Ethics Quarterly, 13, 25-41. 
Rahim, M. M. (2012). Raising corporate social responsibility - The legitimacy approach. Macquarie Journal of Business Law, 9(6), 62-81.

Rover, S., Tomazzia, E. C., Murcia, F. Dal-Ri., \& Borba, J. A. (2012). Explicações para a divulgação voluntária ambiental no Brasil utilizando análise de regressão em painel. Revista de Administração, 47(2), 217-230.

Saat, R., \& Selamat, M. (2014). An examination of consumer's attitude towards corporate social responsibility (CSR) web communication using media richness theory. Procedia - Social and Behavioral Sciences, 155, 392-397.

Salamon, L. M. (1997). Estratégias para o fortalecimento do terceiro setor. In: E. B. Ioschpe (Org.). $3^{\circ}$ Setor: desenvolvimento social sustentado. Rio de Janeiro: Paz e Terra

Santos Silva, V., \& Macagnan, C. B. (2012) Categorias de informações evidenciadas nos relatórios anuais. REDES - Revista do Desenvolvimento Regional, Santa Cruz do Sul, 17(2), 154-174.

Seibert, R., \& Macagnan, C. (2015) Evidenciação das instituições comunitárias de ensino superior: um estudo sob a perspectiva dos públicos de interesse . Contextus Revista Contemporânea de Economia e Gestão, 13(2), 176-209.

Serviço Brasileiro de Apoio à Micro e Pequena Empresa - Sebrae (2009) Oscip: Organização da Sociedade Civil de Interesse Público.

Shaffer, B. (1995) Firm-level responses to government regulation: theoretical \& research approaches. Journal of Management, 21(3), 495-514

Shocker, A. D., \& Sethi, S. P. (1973) An approach to incorporating societal preferences in developing corporate action strategies. California Management Review, 15(4), 97-105.

Slomski, V., Macedo, F. de Q., Tavares, F., Filho, \& Mello, G. R. (2008) Governança corporativa e governança na gestão pública. São Paulo: Atlas

Soldi, A. R., Hatz, C. R., Santos, G. R. dos, \& Silva, M. M. da. (2007) Transparência no terceiro setor: um estudo sobre as organizações filantrópicas. Jovens pesquisadores, 4(1).

Spear, R., Cornforth, C., \& Aiken, M. (2009) The governance challenges of social enterprises: Evidence from a UK empirical study. Annals of Public and Cooperative Economics, 80(2), 247273.

Suchman, M. C. (1995) Managing legitimacy: strategic \& institutional approaches. Academy of Management Review, 20(3), 571-610.

Vergara, S. C. (2014) Métodos de pesquisa em administração (13. ed.). São Paulo: Atlas.

Verrecchia, R. E. (1983) Discretionary disclosure. Journal of accounting and Economics, 5, 179194.

Verrecchia, R. E. (2001). Essays on disclosure. Journal of Accounting and Economics, 32, 97-180. 
Wagenhofer, A. (1990) Voluntary disclosure with a strategic opponent. Journal of Accounting \& Economics, 12, 341-363.

Watts, R. L., \& Zimmerman, J. L. (1978) Towards a positive of the determination of accounting standards. The Accounting Review, 53(1), 112-134.

Weitzner, D., \& Peridis, T. (2011) Corporate governance as part of the strategic process: rethinking the role of the board. Journal of Business Ethics, 102, 33-42.

Whetten, D. A., Rands, G., \& Godfrey, P. (2002) What are the responsibilities of business to society? In: Pettigrew, A., Thomas, H., Whittington, R. Handbook of strategy and management, 373-408. London: Sage.

Wiggill, M. (2014) Donor relationship management practices in the South African non-profit sector. Public Relations Review, 40, 278-285.

Williams, S., \& Adams, C. (2013). Moral accounting? Employee disclosures from a stakeholder accountability perspective. Accounting, Audititng \& Accountability Journal, 26(3), 449-495.

Wood, D. J. (1991) Corporate social performance revisited. Academy of management review, 16(4), 691-718.

Yang, H. I. (2012). Capital market consequences of managers' voluntary disclosure styles. Journal of Accounting and Economics, 53, 167-184.

Yusoff, H., Lehman, G., \& Nasir, N. (2006). Environmental engagements through the lens of disclosure practices: a Malaysian story. Asian Review of Accounting, 14, 122-148.

Zainon, S., Atan, R., \& Wah, Y. B. (2014) An empirical study on the determinants of information disclosure of Malaysian non-profit organizations. Asian Review of Accounting, 22(1), 35-55.

Zittei, M. V. M., Politelo, \& L., Scarpin, J. E. (2013) Nível de evidenciação contábil das organizações do terceiro setor. Anais do Congresso USP de Controladoria e Contabilidade, São Paulo, Brasil, 13.

Recebido em: 08/09/2015

Publicado em: 21/12/2015 